\title{
Editorial: Physics and Seismicity of Rocks
}

\author{
Longjun Dong ${ }^{1 *}$, Guoyang $\mathrm{Fu}^{2}$ and Wei $\mathrm{Wu}^{3}$ \\ ${ }^{1}$ School of Resources and Safety Engineering, Central South University, Changsha, China, ${ }^{2}$ Department of Civil Engineering, \\ Monash University, Melbourne, VIC, Australia, ${ }^{3}$ School of Civil and Environmental Engineering, Nanyang Technological University, \\ Singapore, Singapore
}

Keywords: rock physics, seismicity, fault behavior, rock instability, fault slip, seismic nucleation processes

Editorial on the Research Topic

Physics and Seismicity of Rocks

Understanding the physical mechanisms of rock and exploring the characteristics of seismicity have attracted worldwide attention in solid earth geophysics. Due to the anthropogenic activities such as deep mining and tunneling, large-scale collapses and seismicity frequently occur leading to serious casualties and economic losses. Thus, it is extremely important to prevent the occurrence of disasters or minimize the risk and loss of accidents.

In the past, a great number of experiments have been carried out in an attempt to explain the underlying mechanisms of rocks for various geological phenomena [1,2]. For bringing new breakthroughs of seismicity-related research, innovative experimental techniques, simulation methods, data mining, and geophysical methods are used to extract useful knowledge from the data collected in both experiments and site practices [3-7].

However, the surging demand for space and resources prompts the environment and methods we

OPEN ACCESS

Edited and reviewed by: Alex Hansen, Norwegian University of Science and Technology, Norway

${ }^{*}$ Correspondence: Longjun Dong lj.dong@csu.edu.cn

Specialty section: This article was submitted to Interdisciplinary Physics, a section of the journal

Frontiers in Physics

Received: 23 August 2021 Accepted: 29 September 2021 Published: 21 October 2021

Citation:

Dong L, Fu G and Wu W (2021) Editorial: Physics and Seismicity of Rocks.

Front. Phys. 9:763168. doi: 10.3389/fphy.2021.763168 face to constantly change. The new background, new challenges, and new methods appearing in the physics and seismicity of rocks require further research. Therefore, the main goal of this issue is to fill an essential gap that is greatly missed in this field. We sincerely hope that this issue will be beneficial to the readers to present the recent findings in the field and shed some light on the physics and seismicity of rocks.

Zhao et al. selected a complex of sandstone and C40 concrete mortar to carry out the freeze-thaw cycles test and the uniaxial compression test. The sample water content, the freezing temperature, and the number of freeze-thaw cycles were analyzed based on the factorial design principle. The results showed that the freeze-thaw treatment can significantly reduce the uniaxial compressive strength (UCS) of the sample. The impact of main effects and secondary interaction on unconfined compressive strength was revealed.

Zhang et al. selected the sericite quartz schist coarse-grained soil to carry out the large-scale triaxial consolidated-drained (CD) and consolidated-undrained (CU) shear tests. In order to obtain the stress-strain, deformation, and strength of the sericite quartz schist coarse-grained soil, four different confining pressure conditions were designed in this experiment. They found the stressstrain curve of sericite quartz schist was nonlinearity, compressive hardening and elastic-plastic. Furthermore, the failure mechanism of the samples changed from shearing shrinkage at first and later dilatancy to shearing shrinkage.

Yang et al. designed a shaking table test that a bedding rock slope with weak structural plane was taken as the prototype for studying the acceleration and displacement responses at different positions of the slope. The seismic response and instability mechanism of rock bedding slope under different seismic amplitudes, frequencies and durations are analyzed by adjusting the amplitude and the type of the seismic wave in the experiment. With the increase of the amplitude of the seismic wave, the 
peak ground acceleration (PGA) values of the monitoring points on both sides of the sliding surface showed an opposite trend. The impact of seismic waves on the acceleration response of the bedding rock slope was closely related to its excellent frequency and the natural frequency of the slope.

$\mathrm{Li}$ et al. conducted the Brazilian split tests on granite, marble, sandstone, and limestone. The electron microscope system also was employed to carry out the analysis of fracture morphology. They analyzed the experiment results and found that rock characteristics such as mineral composition may have influence on the b-value and the fracture characteristics of rock. The relationship between acoustic emission signal frequency of rock fracture and the fracture scale was proposed based on the rock characteristics and the distribution characteristics of the frequency spectrum of acoustic emission signals.

Li et al. carried out three cyclic loading and unloading tests with different loading rates and initial cyclic peak stresses for researching the acoustic emission evolution characteristics of saturated limestone under different loading and unloading paths. They analyzed the distribution of signals in different frequency, the development form of the ringing count, and the law of energy evolution. The conclusion summarized in this paper advocated that the roadway should be quickly excavated in the early stage for delaying the most period of fracture behavior.

Chen et al. measured the masses and sizes of the specimens and the $\mathrm{pH}$ values of the acidic solution after saturating the diorite specimens in neutral water and acid solutions. They carried out the triaxial compression tests under the solutions with different $\mathrm{pH}$ values. The mass damage features and mechanical properties of diorite specimens saturated in solutions with different $\mathrm{pH}$ values were analyzed. On this basis, a damage strength model considering acidification was established.

Zhang et al. designed the shaking table experiment on the background of the rock bedding slope with a weak structural plane. The Hilbert-Huang transform (HHT) method was applied to obtain the characteristics of the seismic signal in the Frequency domain. They analyzed the distribution of the energy and the predominant frequency. Finally, the change of the peak value of the marginal spectrum was recognized as an important sign reflecting the development process of the earthquake damage inside the slope.

Li et al. proposed an analytical model to simulate the abutment pressure distribution over the coal in front of the mining face under elastic and inelastic conditions. And a new theoretical formula was derived to discuss the influences of UCS, residual strength, mining height, softening modulus, and deformation angle on the abutment pressure distribution. The field data was applied to verify the validity of the analytical model. The calculated abutment pressure distribution and the widths of the elastic and inelastic zones were compared with the monitoring data. The results showed that the proposed model have high accuracy, which can provide guidance for engineering applications.

$\mathrm{Tu}$ et al. proposed a two-stage constitutive model of cemented tailings backfill (CTB) under uniaxial compression based on the Weibull distribution density function, the strain equivalence principle and the damage mechanics theory. In order to verify the theoretical model, the CTB samples with different solid contents and cement-sand ratios were subjected to uniaxial compression tests. As far as the material itself is concerned, the two variables have a great influence on the sample especially prominent at the peak stress. By comparing the experiment results with the established model, it is found that the failure model of the CTB specimens was mainly tensile failure, and the constitutive model was similar to that of ordinary cement mortar M5. The above research results are helpful to improve the theory of uniaxial compression characteristics of CTB.

Wang et al. selected six parameters including the uniaxial compressive strength, the uniaxial compressive strength, elastic deformation energy index, the ratio of the maximum tangential stress to the uniaxial compressive strength, the depth of the roadway, the integrity coefficient of the rock mass indicators as indicators for rock burst propensity predictions. A finiteinterval cloud model based on the CRITIC algorithm was proposed, which was applied to evaluate the relationships between indicators. By comparing the prediction results of the established model with the monitoring data, the accuracy of the model was verified.

Dong et al. analyzed the stress wave transmission in the course of a single joint and the propagation law of a reflection wave. They treated the joints as rocks in the calculation and proposed the analysis model of stress waves passing through single-joint rock. In view of the above researches, the macro-joint model of stress waves passing through a group of parallel jointed rocks was also established. Finally, the reliability of the models were verified by several tests.

Xie et al. analyzed the blast vibration waveforms from a singledeck blast test and proposed an improved method for multihole blasting seismic wave prediction. The method was applied in the practice and the results showed that it can predict the blast waveforms. The above achievement can provide a new way for design to control blast vibration.

Jing et al. established a model of the high rockfill (HRF) embankment based on the actual project. The construction and operation of the HRF embankment were simulated by a centrifuge test for obtaining the deformation laws of HRF embankment. According to the simulation results, the evolution law of the deformation value and velocity in embankment top and the slope foot during the operation was revealed.

Zhang et al. simulated the support process of tunnel excavation. And they compared simulation results and monitoring data to study the deformation behavior of the surrounding rock and the variation of the stress field in the support structure. The rock occurrence was an important factor that affected the asymmetric deformation behavior in the tunnel with large cross section passing through the soft rock of the coal seam. Several engineering treatment measures such as increasing support structure stiffness were summarized.

$\mathrm{Su}$ and Shen established the deep coal mine stope model containing section coal and rock pillars using the ANASYS software. The response physical characteristics of coal pillars with different widths under the roof shock disturbance 
intensity and frequency from goaf were analyzed based on the dynamic structural system model. Since the model was affected by different shock disturbances, the vertical deformation and the plastic zone occupation ratio of the coal pillar were researched. The results showed that the closer the shock disturbance frequency was to the natural frequency of the model, the more unstable the coal pillar was.

Zhou et al. adopted the discrete element method (DEM) to simulate the SHPB results of acoustic emission (AE) and AE moment tensor. They found that the simulation results were feasible in analyzing the microscopic mechanism of dynamic tensile simulation in rock dynamics. The results showed that the AE simulation was consistent with the macroscopic cracking shown by HS photography. They believed that the ratio of isotropic and deviatoric components of the moment tensor can explain the evolution process of main axial crack and the shear failure zones, which will be different with the traditional method to understand the rock failure mechanism.

Liu et al. simulated the failure process in punch-through shear tests using the discrete element method. By comparing the results of the simulation and experiments, they studied the crack

\section{REFERENCES}

1. Zhang ZZ, Gao F, and Shang XJ. Rock Burst Proneness Prediction by Acoustic Emission Test during Rock Deformation. J Cent South Univ (2014) 21(1): 373-80. doi:10.1007/s11771-014-1950-3

2. Zhang Y, Ma J, Sun D, Zhang L, and Chen Y. AE Characteristics of Rockburst Tendency for Granite Influenced by Water under Uniaxial Loading. Front Earth Sci (2020) 8:55. doi:10.3389/feart.2020.00055

3. Dong L, Hu Q, Tong X, and Liu Y. Velocity-Free MS/AE Source Location Method for Three-Dimensional Hole-Containing Structures. Engineering (2020) 6:827-34. doi:10.1016/j.eng.2019.12.016

4. Yang Z. Key Technology Research on the Efficient Exploitation and Comprehensive Utilization of Resources in the Deep Jinchuan Nickel Deposit. Engineering (2017) 3(4):559-66. doi:10.1016/j.eng.2017.04.021

5. Ma J, Dong L, Zhao G, and Li X. Focal Mechanism of Mining-Induced Seismicity in Fault Zones: A Case Study of Yongshaba Mine in China. Rock Mech Rock Eng (2019) 52:3341-52. doi:10.1007/s00603-019-01761-4

6. Dong LJ, Tang Z, Li XB, Chen YC, and Xue JC. Discrimination of Mining Microseismic Events and Blasts Using Convolutional Neural Networks and Original Waveform. J Cent South Univ (2020) 27(10):3078-89. doi:10.1007/ s11771-020-4530-8

7. Zhu H, Yan J, and Liang W. Challenges and Development Prospects of Ultralong and Ultra-deep Mountain Tunnels. Engineering (2019) 5(3):384-92. doi:10.1016/j.eng.2019.04.009 propagation sequence and the influence of confining stress on effective shear fracture toughness.

The analysis of the physical and mechanical characteristics of the rock requires multiple test and monitoring technology such as acoustics, displacement, and force. Especially in the research of the mechanical property of rock fracture, it is necessary to combine the methods of source location, source identification, and focal mechanism inversion for analysis. As the field of rock engineering becomes more extensive and the problems are more complicated, the research of the physics and seismicity of rocks which considers rock structures [8] and velocity variation [9] will be the trend of the future research, which can provide the assistance for disaster early warning and risk control in practical engineering.

\section{AUTHOR CONTRIBUTIONS}

LD and GF drafted the first version of the editorial. LD and WW revised the first draft and made contributions about papers they edited.

8. Dong L. J., Tong X. J., Hu Q. C., and Tao Q.. Empty Region Identification Method and Experimental Verification for the Two-Dimensional Complex Structure. Int. J. Rock Mech. Min. (2021) 147:104885. doi:10.1016/ j.ijrmms.2021.104885

9. Dong L. J., Tong X. J., and Ma J.. Quantitative Investigation of Tomographic Effects in Abnormal Regions of Complex Structures. Engineering. doi:10.1016/ j.eng.2020.06.021

Conflict of Interest: The authors declare that the research was conducted in the absence of any commercial or financial relationships that could be construed as a potential conflict of interest.

Publisher's Note: All claims expressed in this article are solely those of the authors and do not necessarily represent those of their affiliated organizations, or those of the publisher, the editors and the reviewers. Any product that may be evaluated in this article, or claim that may be made by its manufacturer, is not guaranteed or endorsed by the publisher.

Copyright (c) 2021 Dong, Fu and Wu. This is an open-access article distributed under the terms of the Creative Commons Attribution License (CC BY). The use, distribution or reproduction in other forums is permitted, provided the original author(s) and the copyright owner(s) are credited and that the original publication in this journal is cited, in accordance with accepted academic practice. No use, distribution or reproduction is permitted which does not comply with these terms. 